\section{Buried bumper syndrome after percutaneous endoscopic gastrostomy in children and adolescents}
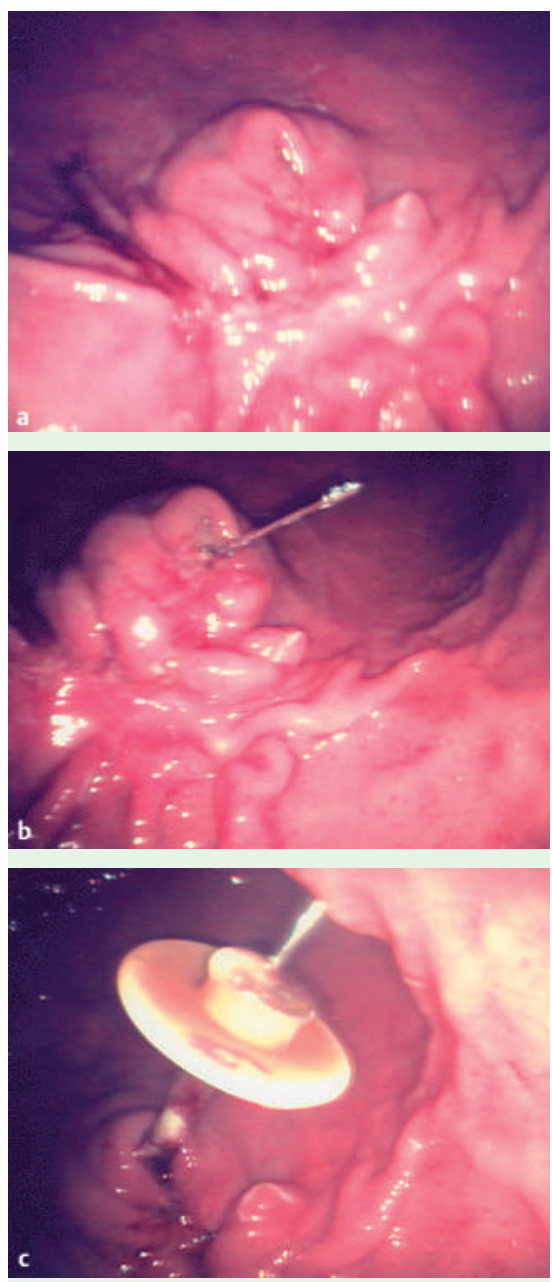

Fig. 1 Endoscopic view of a an immobile internal flange completely covered by gastric mucosa, b a metal probe forwarded through the tube into the gastric lumen, $\mathbf{c}$ the stiffened probe and the bumper, which was freed after application of constant pressure from outside.

The percutaneous endoscopic gastrostomy (PEG) has become the preferred method for enteral feeding in children with prolonged insufficient oral intake [1]. A complication of the PEG is the migration of the internal flange into the gastric or abdominal wall, referred to as "buried bumper syndrome" (BBS). The prevalence in adults is $2.0 \%-2.9 \%[2,3]$. Among the past 700 children who received a PEG under our care, a total of 17 BBS were observed (prevalence $2.4 \%$ ). The un-
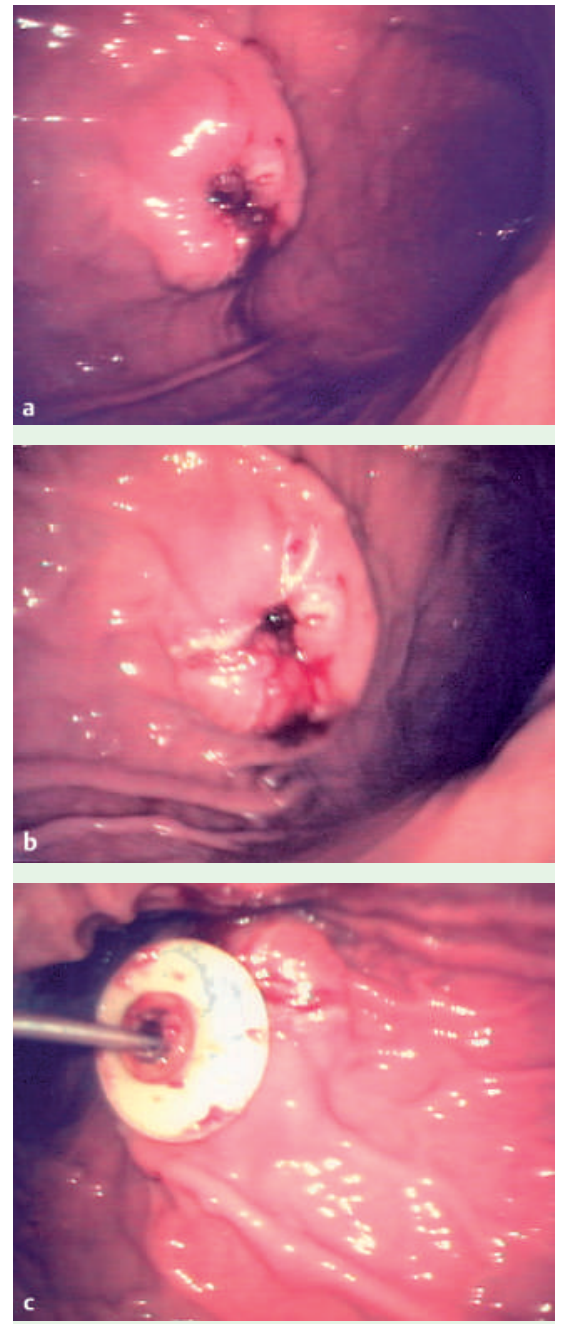

Fig. 2 Endoscopic view showing a an internal flange covered by gastric mucosa, which could not be freed by the push technique solely, $\mathbf{b}$ radial incisions into the covering mucosa created by a needle knife in order to create a mucosal opening, $\mathbf{c}$ the now mobilized flange with a stiffening metal probe.

derlying diseases in the children were mental retardation with central dysphagia $(n=13)$, congenital heart disease $(\mathrm{n}=3)$ and inherited metabolic disease $(n=1)$. This reflects proportionally the general distribution of the PEG indication in pediatric patients [1]. The median age of the BBS patients was 6 years and 9 month (2.0-18.5 years), the median time BBS was found after PEG placement was
19 months (2-48 months). Nine patients were cared for by their parents, in eight patients a professional caregiver was responsible for the child. In all cases the used feeding tube was a Freka $\mathrm{CH} 15$ model (Fresenius GmbH, Germany). Endoscopic therapy was mostly successful by the push and pull technique $(n=8)$ ( Fig. 1), or if that failed the gastric mucosa was incised by a needle knife or fistulotome $(n=2)$ ( $\bullet$ Fig. 2). Whenever clinical signs (internal bumper palpable through the skin), endoscopic findings (flushing or probing the tube impossible), or imaging studies indicated that the flange was located outside the stomach wall the patient was referred for surgery $(n=7)$.

Poor postoperative care without appropriate regular mobilization is an attributing factor to the development of BBS. Only two pediatric cases with a complete BBS reporting in detail course and therapy have been published so far [4]. Mostly incomplete BBS "intragastric buried or extruded tube or button" are observed, which required only a replacement of the device [5].

Children with BBS may present with a number of symptoms: a leaking tube, inability to infuse feedings, and in particular an immobile tube. In these cases endoscopy is indicated to diagnose BBS in a timely fashion. Endoscopic therapy is also often possible in children.

\section{Endoscopy_UCTN_Code_CPL_1AH_2AI}

\section{H. Köhler ${ }^{1}$, T. Lang ${ }^{2}$, R. Behrens ${ }^{3}$}

${ }^{1}$ Kinder- und Jugendklinik, Universitätsklinikum Erlangen, Germany

2 Klinik St. Hedwig, Krankenhaus Barmherzige Brüder, Regensburg, Germany Zentrum für Neugeborene, Kinder und Jugendliche, Südklinikum, Nürnberg, Germany 


\section{References}

1 Behrens R, Lang T, Muschweck H et al. Percutaneous endoscopic gastrostomy in children and adolescents. J Pediatr Gastroenterol Nutr 1997; 25: 487-491

2 Braden B, Brandstaetter M, Caspary WF et al. Buried bumper syndrome: treatment guided by catheter probe US. Gastrointest Endosc 2003; 57: 747-751

3 Horbach T, Teske V, Hohenberger $W$ et al. Endoscopic therapy of the buried bumper syndrome: a clinical algorithm. Surg Endosc 2007; 21: 1359-1362
4 Hodges EG, Morono JU, Nowicki MJ. The buried bumper syndrome complicating percutaneous endoscopic gastrostomy in children. J Pediatr Gastroenterol Nutr 2001; 33: $326-328$

5 Ségal D, Michaud L, Guimber D et al. Late-onset complications of percutaneous endoscopic gastrotomy in children. J Pediatr Gastroenterol Nutr 2001; 33: 495-500
Bibliography

DOI $10.1055 / \mathrm{s}-2007-995552$

Endoscopy 2008; 40: E85-E86

(c) Georg Thieme Verlag KG Stuttgart · New York . ISSN 0013-726X

\section{Corresponding author}

\section{H. Köhler MD}

Kinder- und Jugendklinik

Pädiatrische Gastroenterologie

Universitätsklinikum Erlangen

Loschgestr. 15

91054 Erlangen

Germany

Fax: +49-9131-8533375

henrik.koehler@uk-erlangen.de 